\title{
THE STATE OF APPLIED INFORMATION AND COMMUNICATION TECHNOLOGIES AND E-BUSINESS PRACTICES IN BULGARIAN SMALL AND MEDIUM-SIZED ENTERPRISES
}

\author{
Melina Neykova \\ Department of Computer Systems and Informatics \\ University of Forestry \\ 10 Kliment Ohridski blvd., Sofia, Bulgaria, 1797 \\ melina.neykova@gmail.com \\ Radoslav Miltchev \\ Department of Computer Systems and Informatics \\ University of Forestry \\ 10 Kliment Ohridski blvd., Sofia, Bulgaria, 1797 \\ rmiltchev@ltu.bg
}

\begin{abstract}
Small and medium-sized enterprises (SMEs) represent the dominant form of business organization in the economic system globally and play an important role in the economic development and increased competitiveness of the economy, both in Bulgaria and in the European Union (EU).

The presented article is scientifically applicable in nature and is based on an extensive survey whose purpose is to analyze the current state of information and communication systems in small and medium-sized industrial enterprises in Bulgaria. Based on the collected and processed information the study reveals the current state and existing practices and problems related to the operation and maintenance of specialized information and communication systems and e-business technologies. The presented survey reveals important aspects related to the security of information resources in organizations in order to overcome existing obstacles and disadvantages in the e-business system and to improve it in the future, which will lead to its increased sustainability and competitiveness in the economic market.
\end{abstract}

Keywords: information and communication technologies, e-business, information security, information resources.

\section{Introduction}

Small and medium-sized enterprises (SMEs) represent the dominant form of business organization in the economic system globally and play an important role in the economic development and increased competitiveness of the economy, both in Bulgaria and in the European Union (EU). In the 25 EU Member States, there are over 21 million SMEs, which provided 88.8 million jobs throughout the EU [1].

According to the latest data of the National Statistical Institute (NSI), the number of enterprises in the non-financial sector in Bulgaria in 2015 is 326,380, where the number of micro, small and medium-sized enterprises is predominant (99.8\%) [2]. The observed tendency in the total number of SMEs is growing, in contrast to the sector of large enterprises, with microenterprises being the most numerous [3-5].

The surveyed data show that many SMEs experience financial problems, which suggests cost-cutting and business activity optimization. Taking into account the importance of SMEs in the economy, it must be emphasized that at such a time the ability to effectively use modern information and communication technology (ICT) solutions for electronic business (e-business) plays a crucial role in increasing the sustainability of enterprises and occupies strategic business positions in the newly created Internet economy [6-8]. The global network is being used more and more actively as a tool for advertising the services and products offered by enterprises. It is a mandatory aspect in transforming a traditional business into an electronic one. So, the managers of the enterprises that are seeking to expand the market and increase their competitiveness are faced with the decision of not whether it is time for such a transformation, but how to do it in the best possible way [9]. 
The clarification of the theoretical justification of the positions of various Bulgarian and foreign authors on e-business and its development on the basis of the introduction of innovations and possible concepts for advanced ICT [9-16] reveals the possibility of improving the operation of Bulgarian SMEs and increasing their competitiveness. Apart from theoretical formulations, however, the desired results can be achieved by determining the actual state of ICT and whether it is necessary to introduce innovative solutions for the development of e-business systems in SMEs. It is necessary to determine the capabilities, needs and restrictions that exist both inside the enterprises and in the surrounding business environment. For this purpose, the research carried out involves an integrated analysis, which aims to reveal the actual state of currently applied ICT practices related to the protection of access and security of information, as well as to ensure uninterrupted access (24 hours/7 days) to information e-business resources in the surveyed group of SMEs.

\section{Materials and Methods}

\section{1. Empirical basis of the research of applied ICT and e-business practices in Bulgar-} ian SMEs

In the present study a questionnaire survey was conducted independently as a basic instrument for collecting empirical data during the period April-May 2015 at 70 Bulgarian enterprises, where the prevailing part of them are from Sofia, Blagoevgrad and Veliko Tarnovo regions. The survey takes into consideration the advantages of questionnaire surveys as a method which is suitable for the collection of a significant amount of information at minimal cost [17], where in view of the advantages of the modern Web-based surveys, one part (60 in number) of the inquiries were filled out on paper and the remaining (201 in number) were conducted online by filling in a specially developed online form. The inquiries were conducted among 261 participants, $57 \%$ of whom are in managerial positions and the remaining $43 \%$ of whom are in subordinate positions. The affiliation of the respondents according to the number of personnel is as follows: $33 \%$ of respondents work in micro-enterprises; $33 \%$ - belong to small enterprises, and the remaining $24 \%$ - belong to the group of medium-sized enterprises. A total of $90 \%$ of respondents are classified as belonging to SMEs but only $10 \%$ of respondents work in large enterprises (with over 250 employees) [4]. According to data, obtained from the survey, the predominant form of ownership of the studied organizations is private $-68 \%, 23 \%$ of respondents are classified as working in state organizations, while only $9 \%$ work in mixed enterprises. It must be taken into account, that the role and importance of this factor for the level and quality of ICT is associated with the budgetary possibilities and restrictions, especially in state enterprises. The questionnaire includes 60 questions in order to get a more complete picture of the state of ICT systems and the applied e-business measures in the studied group of Bulgarian SMEs.

\section{2. Restrictive conditions of conducted research of applied ICT and e-business prac- tices in Bulgarian SMEs}

The present article analyses only part of the survey results that are related specifically to the study of the actual state of the internal ICT networks and e-business systems of the enterprises, the preparation and the level of skill of the employees working in the ICT sector and the technical security and protection of the access to information resources of enterprises. The conducted research is representative in nature, so the investigations and the performed analysis, conclusions and assessments of the state of applied ICT practices in organizations are valid only for the object of study. The group of the large participating companies is not a subject of the present study, but has been investigated as a necessary party for comparison and in order to make a clearer assessment of the state of SMEs in the country.

3. Results of conducted research of applied ICT and e-business practices in Bulgarian SMEs In recent years, the introduction of ICT solutions is implemented more and more actively in Bulgarian SMEs [18] which is due to the new managerial idea of achieving a strategic advantage through ICT investments and their direct impact on improving the quality of automated business 
activity in enterprises. This assertion is supported by the results, obtained from the survey on the issue of to what extent the development of the business activity of organizations depends on ICT. From the received information it is clear that almost all of the respondents (97\%) think that no business activity can be implemented without ICT, which means that the surveyed enterprises must not only maintain their ICT, but also introduce advanced solutions to improve their overall strategy for e-business information support.

The availability of computers (especially a new generation of computers) and a local computer network (wired or wireless) in the organizations is the basic condition for the construction of an ICT infrastructure as well as for a variety of e-business purposes. The survey data confirm that regardless of the size of the enterprises, almost all of the studied organizations have developed a computer network which they use in their business activity. The information clearly indicates that the practice in various sized companies is to use different number of computers. So, while in micro enterprises the predominant number is less than 5 computers, in small enterprises the predominant number is more than 5 and up to 10 PCs. And the majority of medium-sized and large enterprises tend to use more than 10 computers in their business. This circumstance is directly related to the scope of activity of enterprises and their financial capabilities, and the need to have skilled IT specialists and to create an ICT maintenance unit should be taken into consideration.

A compulsory aspect of the management of IC systems is the use of various software products in the business activities of organizations and the data received from the survey indicate that the surveyed organizations use the following software products:

- office applications (word processing systems and spreadsheet programs, applications for reading an email, browsing the Internet, etc.) - $42 \%$ of respondents;

- accounting software $-30 \%$ of respondents;

- programming software for human resources management - $16 \%$ of respondents;

- specialized business programs that are related to the subject of activity of the organization $-11 \%$ of respondents;

- other programs $-1 \%$ of respondents.

In this context, it is appropriate in different organizations to have a separate structural unit which is responsible for the maintenance of computer systems and software. But the results of the conducted survey show that the majority of respondents $-70 \%$ - confirmed that such a structural unit is not available in their organizations and these results testify to the existence of risks to the information security and confidential data of the organizations and the possible loss of business benefits. The prevailing number of respondents works in micro and small enterprises (89\%). This result can be explained by the insufficient financial resources which are necessary for setting up a department, responsible for the maintenance of computer systems and software as well as the impossibility to employ qualified ICT specialists, who are responsible for the timely implementation of effective technological innovations that ensure the confidentiality, integrity and accessibility to corporate information assets and resources. Furthermore, despite the fact that according to $97 \%$ of respondents the business activities of their organization are directly dependent on ICT resources, the majority of the surveyed companies $(62 \%)$ do not have ICT staff or, in a greater number of cases, it is insufficient and consists of 1 to 3 people.

In recent years, a growth trend in the use of ICT is observed across Bulgarian businesses, where the share of enterprises that have access to the Internet (91.4\%) has a direct influence [18]. These data are also confirmed by the results, obtained in this survey, which show that the rate of Internet connectivity in the monitored enterprises is very high and almost all respondents (97\%) confirm the presence of an Internet connection that is used for various business activities (Fig. 1).

The low share of enterprises which implement e-commerce makes an impression in the obtained results, which can be interpreted in close relationship with the backlog of the country against the general background of development in Europe [19] and as a serious indicator of the need for innovative solutions for the development of e-business systems in Bulgarian enterprises.

The development of e-business activity of the organizations should be presented on the Web via an attractive website. It should be as up-to-date as possible, with rich content and an integrated Internet concept. In this way, the organization will send its fundamental marketing message and 
build its reputation among customers, partners and counterparties on an international scale. The enterprises participating in this study make no exception, and almost all of them have built a website $(92 \%)$. The data, obtained from the inquiry on the influence that the company website has on the development and competitiveness of the business activity of surveyed organizations, indicate that almost all respondents $(93 \%)$ reported that the availability of an electronic website affects the activity of enterprises. According to the majority of respondents (53\%), this influence is great and it has led to a sharp increase in the development and competitiveness of the implemented business activity. In addition, in answer to the question of whether the competitors of the studied organizations have a website, most of the respondents ( $72 \%$ ) gave a definite positive response, which in turn is another confirmation that any enterprise that wants to strengthen its presence in the market and expand the scope of its business activities, must make a name for itself in the online space.

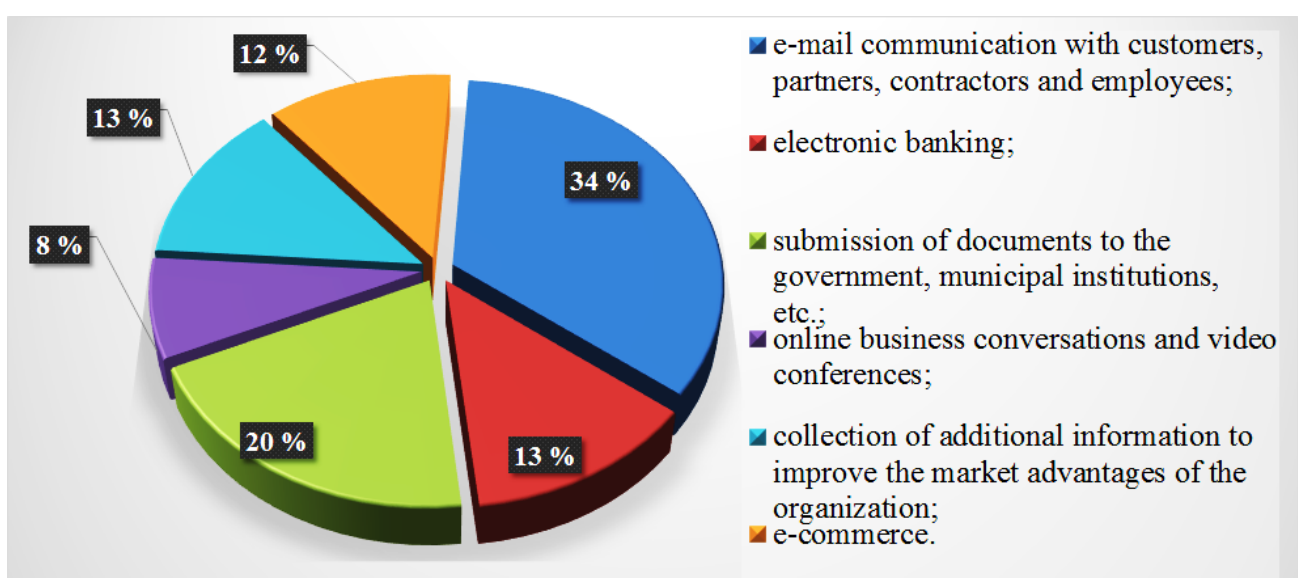

Fig. 1. Purposes of Internet use as part of the business activity of the organizations

The dynamic generation of various information technologies and devices and the ever more active implementation of e-business require the need to ensure processes that are related to the confidentiality and integrity of information assets of the organizations and the availability and authentication of the authenticity of employees, partners and customers. The conducted study revealed problems with the undervaluation of e-business systems, which are exacerbated when considering the state of information security in the surveyed enterprises. In this sense, more than half of the respondents $(55 \%)$ are not aware of and cannot answer the question of whether analyses were conducted to assess the state of information and communication support and the level of information security in the organizations. Moreover, $42 \%$ of respondents in the analyzed organizations are in managerial positions, which is a very high percentage and this can be regarded as a reason for concern in view of the issues discussed.

At the same time, the indicated problem could be linked with the inability to acquire sufficient timely information on ICT issues and take relevant measures and approaches for the protection of and access to information assets due to financial difficulties or lack of ICT skills and qualified personnel. It follows from the above that the majority of the surveyed organizations are not capable of performing periodic innovations of their ICT systems, including of introducing and implementing active measures (through appropriate technological innovation) that help to increase IC and prevent critical risks and threats to the confidential information resources of the organization.

In addition, the majority of respondents (67\%) are of the absolute opinion that no properly documented information security policy exists, that taking into account the affiliation of respondents according to the size of the companies shows that this problem is concentrated mainly in micro and small enterprises ( $85 \%$ ). This, in turn, can be interpreted as a serious risk and a threat to the confidential information assets and resources of the surveyed organizations. Thus, the e-business system can be seriously threatened and a situation can occur where competitive organizations and business entities can acquire key data and important information. 
Based on the information, obtained in the survey on the type of methods that are used to identify the staff when accessing information assets in the organizations, a username and password or personal identification number are indicated in the first place as the predominant method of identification (66\%) (Fig. 2). The second most common methods of identification, used by the surveyed enterprises, are the identifications performed by means of personalized cards $(21 \%)$ or electronic cards $(9 \%)$. Only $2 \%$ of all surveyed respondents confirmed that their organizations use fingerprint identification. Biometric technologies that provide a high degree of precise identification [20-23] are not used by the surveyed group of organizations. Thus, taking into account the global data and studies related to breaches in security of the information resources of organizations reveals disturbing facts about the existing risks in the corporate information system, including essential disadvantages of the approaches based on the possession of physical objects and those based on the knowledge of certain information, as they can be forgotten, lost, provided to somebody else, or even stolen by ill-intentioned people.

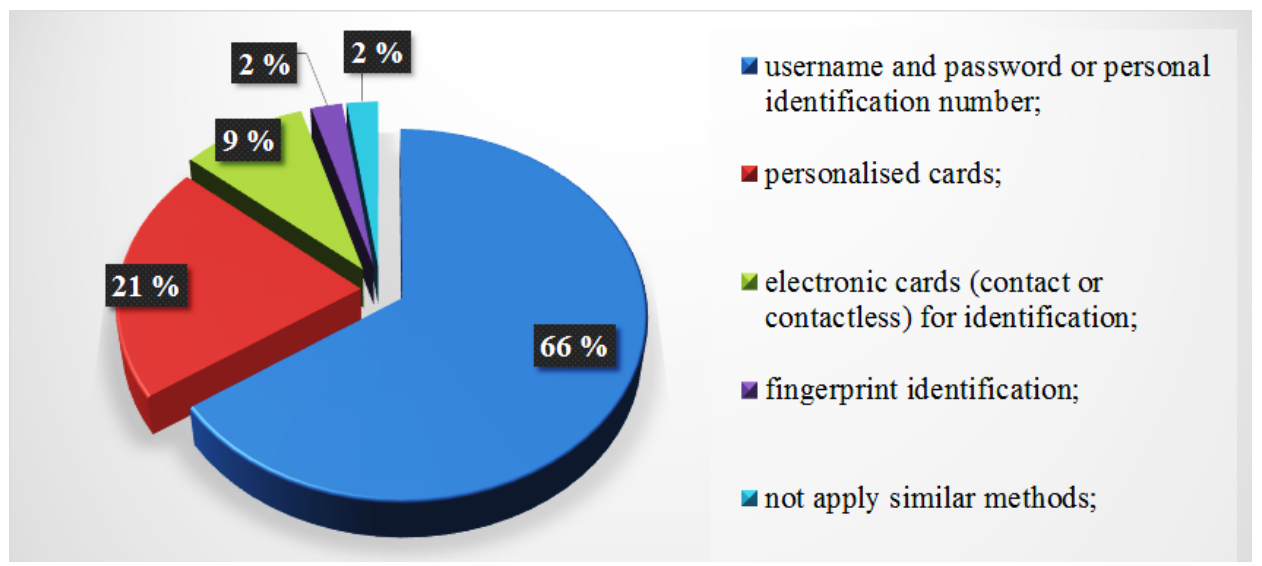

Fig. 2. The use of the methods of identification by staff to control the access to information assets and resources

These arguments are supported by results from the survey question about the existing disadvantages of the methods of identification of employees when accessing the information resources and assets of the organization (Fig. 3).

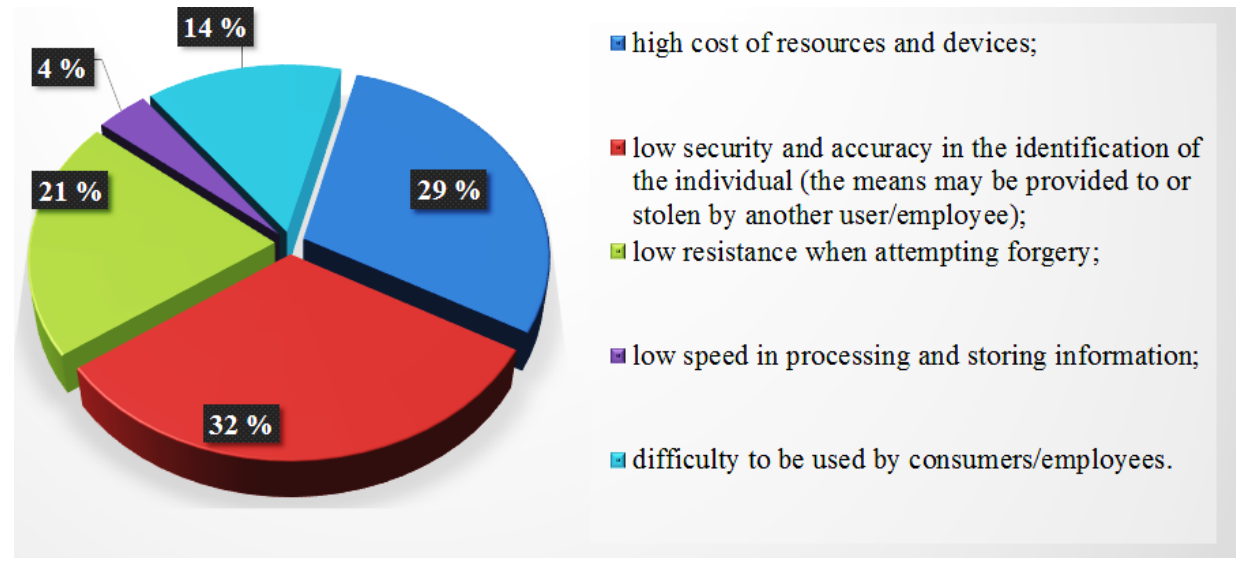

Fig. 3. Disadvantages of the methods of identification when accessing information resources

In this regard, the study makes an inquiry on whether the organizations applied methods to increase the control over employee access to information resources and assets. The results again showed a poorly localized attention and insufficiently active measures in this direction, in consequence of which problems can occur in the business activities of organizations and confidential 
data and business benefits can be lost. In this sense, $85 \%$ of respondents agree that their enterprises do not use methods for increasing the access control of the employees. At the same time, $70 \%$ of the respondents find that there is a need to further increase the level of security when employees access the information resources and assets in the organization. Moreover, $60 \%$ of them are employees in managerial positions, which fact emphasizes the depth of the assessment and the urgent necessity of the introduction of actual measures.

When providing access to the network information systems and e-business assets of the organizations in continuous mode $24 / 7$ to employees, partners, contractors and customers, a server system must be ensured, which requires increased use of electricity, cooling as per the parameters of the machine and permanent (software and hardware) maintenance. In the conducted research, more than half of the respondents ( $72 \%$ ) confirmed that their organizations have a server/servers. But when examining the storage requirements for the server/servers, it becomes clear that: $20 \%$ of the respondents claim that the servers used by their enterprises are stored by external organizations; $28 \%$ confirm that the servers are stored in the same way as all other computers in the organization, without meeting the requirements that are needed to overcome the premature aging of the equipment and a possible failure to operate $24 / 7$. Such negative influences could lead to missed business opportunities and loss of clients and partners for the organizations.

In addition, more than $75 \%$ of respondents have indicated that their enterprises do not have an uninterruptible power system (UPS - Uninterruptible Power Supply) during the operation of the server/servers, which is a prerequisite for the loss of key and critical data and information in case of unexpected disruptions of electricity or electric shocks.

The survey reveals the fact that almost all respondents ( $94 \%$ ) claim that the monitored enterprises use devices for the climatisation of the work environment (temperature and humidity), which are air conditioning (61\%), central climatisation (11\%) and ventilation (22\%). However, almost half of them $(49 \%)$ are convinced that it is necessary to improve the level of control of the temperature and humidity on the premises where information and communication devices are stored.

It is clear from the data in the conducted study that the majority of investigated businesses $(95 \%)$ do not use spare devices for monitoring the ICT environment (a specialized electronic device for precise air-conditioning and control of the temperature and humidity). Obviously, this is one of the serious shortcomings in terms of the exploitation of the ICT devices and server machines, because such innovative technologies could facilitate the performance of remote monitoring of communication premises in organizations and warn of critical conditions of the surrounding environment, which may adversely affect the entire information resource of the organization and could result in the loss not only of critical data, but also of expensive information and communication equipment.

In conclusion, almost all of the surveyed organizations have set up an Internet connection and an electronic website, which are some of the basic steps to build and implement a successful e-business. But it should be noted, that these resources should be available 24 hours a day, 7 days a week, and 365 days a year, and this is the reason why necessary ICT equipment and qualified support for continuous operating mode must be ensured. However, the majority of the surveyed organizations do not have an ICT department and enough staff to maintain computer systems and software, which necessitates the use of third party services. And this is a deficiency that shows insufficient assessment of the importance of the management of the e-business ICT system.

\section{Conclusions}

1. Many of the surveyed organizations do not correctly assess the scope of the e-business system (including their managers) by failing to take into account the need to assess and support specialized information systems and resources, including portal sites, e-commerce systems for managing customer relationships and more. This fully applies to the surveyed SMEs that lack sufficient financial resources.

2. In the surveyed organizations there is a problem with the elaboration of an adequate assessment of the state of e-business ICT resources. Moreover, the managing staff underestimates the importance and nature of information security. 
3. The obtained survey data are disturbing and suggest risks to both the uninterrupted access to the information assets of the enterprises and to the confidential data and information security, because servers are a computer resource with critical information for organizations that need to be maintained 24/7 under the operating requirements, set out by the manufacturer.

4. Most of the organizations underestimate the importance and the role of information security as a key aspect of sustainability, development and competitiveness of the business activity globally. This in turn can be a serious risk and threat to the confidential information assets and resources of the surveyed organizations and can result in the occurrence of critical situations, which is fully applicable to the surveyed micro and small enterprises.

5. The organizations are characterized by a lack of activity in the introduction of innovations in the sphere of information support and a low level of information security of the applied methods of identification, which shows an urgent need for the implementation of appropriate technological solutions that are available for the limited budgetary possibilities of SMEs in the country.

The performed analysis and obtained results are a logical basis for the future development of an approach for the introduction of technological innovations by means of which to improve the e-business strategy in Bulgarian SMEs, prepared on the basis of popular good international practices and trends, and comply with existing factors and prerequisites in Bulgarian enterprises.

\section{References}

[1] European Union (2015). User guide to the SME Definition, 60. doi: 10.2873/620234

[2] National Statistical Institute. Republic of Bulgaria. (2015). Non-financial Enterprises. Available at: http://www.nsi.bg/en/content/8035/non-financial-enterprises

[3] Small Business Act (2015). Reference book. Bulgaria, 2.

[4] Law for SMEs in Bulgaria, Prom. SG. 84, 1999. Final. Am. SG. 82 of 2009, Art. 3.

[5] National Statistical Institute. Republic of Bulgaria (2015). Business Demography. Available at: http://www.nsi.bg/en/content/13218/business-demography

[6] Kogut, B. (2004). The Global Internet Economy. MIT Press, 540.

[7] Barfield, C., Heiduk, G., Welfens, P. (2003). Internet, Economic Growth and Globalization: Perspectives on the New Economy in Europe, Japan and the USA. Berlin, Heideberg: Springer-Verlag, 322. doi: 10.1007/978-3-540-24761-6

[8] Barua, A. (2000). Measuring the Internet Economy. Center for Research in Electronic Commerce, University of Texas at Austin, 164.

[9] Gloor, P. (2012). Making the e-Business Transformation. London: Springer-Verlag, 179. doi: 10.1007/978-1-4471-0757-6

[10] Chaffey, D. (2007). E-Business and E-Commerce Management: Strategy. Implementation and Practice. Ed. 3. Harlow: Prentice Hall, 628.

[11] Combe, C. (2006). Introduction to E-Business. Routledge, Butterworth-Heinemann, 448.

[12] Turban, E., King, D., Lee, J., Liang, T., Turban, D. (2015). Electronic Commerce: A Managerial and Social Networks Perspective. Springer International Publishing Switzerland, 791. doi: 10.1007/978-3319-10091-3

[13] Miltchev, R., Neykova, M. (2015). The Impact of Technological Innovations to The Sustainability of the E-Business Systems of Organizations Operating in the Tourism Sector. Proceedings of 3rd International Scientific Conference Tourism in Southern and Eastern Europe 2015, $223-233$.

[14] Iliev, G., Miltchev, R. (2014). E-business and Planned Obsolesces in the Lifecycle of Information Technology. Reports International Scientific Conference "Economics and Management in a Turbulent Environment", Vol. 1. Academic Publishing, 75-80.

[15] Miltchev, R., Iliev, G. (2014). Information Economy, asymmetry of Information and Turbulence of Business Environment. Reports International Scientific Conference "Economics and Management in a Turbulent Environment", Vol. 1. Academic Publishing, 438-445.

[16] Miltchev, R., Iliev, G. (2014). Information Technology in the Conditions of Globalization and Variability of the Economic Environment. Reports International Scientific Conference "Economics and Management in a Turbulent Environment”, Vol. 1. Academic Publishing, 446-452.

[17] Kotler, P., Armstrong, G. (2010). Principles of Marketing. Prentice Hall, 744. 
[18] National Statistical Institute. Republic of Bulgaria (2014). Main results of research on the Information Society in the enterprises in 2014. Available at: http:/www.nsi.bg/sites/default/files/files/pressreleases/ICT_ent2014_GLINCXB.pdf

[19] Lange, J., Longoni, A., Screpnic, A. (2012). Online payments 2012. Ecommerce Europe edition. Version 1.1, 92. Available at: http://epca.de/sites/default/files/documents/1204\%20Online\%20payments\%20 2012_EN_v1.1_online.pdf

[20] Maltoni, D., Maio, D., Jain, A. K., Prabhakar, S. (2009). Handbook of Fingerprint Recognition. London: Springer, 494. doi: 10.1007/978-1-84882-254-2

[21] Edgington, B. (2007). Your quest for the ideal biometric: is it in vain? Introducing Hitachi's Finger Vein Technology. A White Paper. Hitachi Europe Limited, 9. Available at: http://www.hitachi.eu/veinid/ documents/veinidwhitepaper.pdf

[22] Boone, G., Huang, J., Spiegeleire, S., Sweijs, T. (2009). Future Issue Biometrics. The Uncertainty of Identification \& Authentication: 2010-2020. The Netherlands: The Hague Centre for Strategic Studies, 38. Available at: http://hcss.nl/sites/default/files/files/reports/01.06_.2009_-_Future_Issue_-_Biometrics_pdf

[23] Jung, M. (2005). Biometric Market and Industry Overview. Brussels, Belgium: International Biometric Group, 12. Available at: http://www.wcoomd.org/fr/events/event-history/2005/ / /media/96665922235E422E8B7BA8FA9CD8CA0E.ashx 